\title{
Aptamer Technology
}

National Cancer Institute

\section{Source}

National Cancer Institute. Aptamer Technology. NCI Thesaurus. Code C20096.

Technologies that utilize aptamers for biosensors, diagnostic assays, therapeutics, etc. 